\title{
A UNIDADE DO PARTICULAR E AS ARESTAS DA CONSCIÊNCIA MODERNA NO PROJETO DE UMA POLÍTICA VINDOURA
}

\author{
Tereza de Castro Callado ${ }^{1}$
}

\begin{abstract}
RESUMO
$\mathrm{Na}$ teoria do conhecimento de Walter Benjamin, o particular se articula com a dimensão da força de sua unidade, quando, em um estado de justaposição com outras singularidades, cede à maneira de uma mônada, à sua capacidade de percepção, para comunicar a si mesmo diante do macrocosmo. Essa concepção epistemológica, que emoldura a tematização política de Benjamin visa às arestas da "consciência esclarecida", precisamente na estrutura da subjetividade moderna. O apelo à mutualidade e reciprocidade característico da mônada aponta para a exigência de uma tematização política do convívio entre os homens, reelaborada para acolher o diferente no universo democrático dos elementos isolados e heterogêneos da totalidade humana, com vistas à comunidade política vindoura.
\end{abstract}

Palavras-chave: Singular, Mônada, Heterogeneidade, Diferente, Política,. Comunidade

\section{THE UNITY OF THE PARTICULAR AND THE EDGES OF MODERN CONSCIOUSNESS IN THE DESIGN OF A YET TO COME POLITICS}

\begin{abstract}
In the theory of knowledge of Walter Benjamin, the analysis of the particular articulates with the size of the force of his unit, when in a state of juxtaposition with other singularities, it gives way to a monad, his power of perception, to communicate itself towards the macrocosm. This epistemological conception which frames the political philosophy of Benjamin, aim on the edges of the "enlightened conscience" and precisely on the structure of modern subjectivity. The sense of mutuality and reciprocity characteristic of monads points to a new policy theme of interaction among men elaborated to accept the different, the democratic universe of heterogeneous and isolated from human whole, with a view to the coming political community elements.
\end{abstract}

Keywords: Particular, Monad, Heterogencity, Different, Political, Community

A constatação de uma validade para o singular, como será realizada aqui, pretende contornar não apenas o viés político da história dos particulares, enquanto se constitui também como um agente autorizado no domínio das ciências que procedem à práxis, e, principalmente, à filosofia política. A dificuldade desse

\footnotetext{
1 Tereza de Castro Callado é doutora em Filosofia (USP- 2005) e em Literatura Brasileira (USP1997). É professora de Filosofia da Universidade Estadual do Ceará e autora de "Walter Benjamin A Experiência da Origem" (Eduece,).
} 
procedimento - a cristalização do particular - é muitas vezes impelida pela avalanche de um universal, no conceito, extraído da média, o que empana sua visualização. Sabe-se que a tradição filosófica sempre privilegiou o universal. Diante da aporia filosófica - o espaço usurpado ao particular - observamos a crítica benjaminiana: "É absurdo ver no universal uma simples média. O universal é a ideia”. ${ }^{2}$ Para transpor o obstáculo da média conceitual Benjamin propõe recriar o método cognitivo das ciências humanas habilitando-as à assimilação das diferenças da realidade, a partir de seus extremos. Tendo por fim reduzir o raio de atuação desse pseudo universal, a atenção será votada à relação do particular com a ideia, procedimento esse que irá desvelar conceitualmente sua participação na totalidade. Essa interface da reflexão acerca de um saber para a Modernidade exige a mobilização de ideias acerca do topus político adequado à constituição das diferenças enquanto elementos imprescindíveis à totalidade. Para Benjamin é na unidade desse particular - não alcançável pela ciência positiva - que se encontra a verdade. Uma vez que é vetado à filosofia falar em tom de revelação, essa verdade se auto representará na ideia. Um recurso do método para preservar a verdade se manisfesta na fragmentação. A fragmentação seria um dispositivo para manter incólume, às generalizações conceituais, a unidade do particular. $\mathrm{Na}$ auto defesa contra a massificação, ele permanece um particular, e enquanto particular contribui enquanto elemento constituinte da totalidade. É da massa que a política ideológica suga seu poder e não da unidade do particular. Sabemos, por isso, que é na massa que o sistema constrói a dominação. No fragmento extraído do cotidiano e que se reproduz no fragmento linguístico reside o método para a teorização política, ou seja a filosofia política de Benjamin está disposta em toda a sua produção, parecendo muitas vezes sob a aparência de difícil acesso. Isso se deve ao método do desvio (Umweg), que tem por objetivo não limitar a ideia às leis da demonstrabilidade conceitual. Ao contrário, tendo em vista a variabilidade do mundo real seu fim é comprovar que a verdade não pode ser capturada por uma rede de conhecimentos, ${ }^{3}$ como se essa verdade voasse de fora para dentro. Ao olhar da argumentação discursiva eloquente, como é de praxe em uma defesa teórica, sua aparição é imperceptível, uma vez que a verdade está isenta de intenção. O contrário se dá

\footnotetext{
2 BENJAMIN, Origem do drama barroco alemão, Tradução de Sérgio Paulo Rouanet, São Paulo: Brasiliense, 1984, p. 57

3 BENJAMIN Opus cit, p. 50.
} 
com o saber, que se confunde com posse (Erkenntnis ist ein Haben) ${ }^{4}$ e é apropriado na consciência, "mesmo que se trate de uma consciência transcendental". A verdade como ser indefinível, não possui nenhuma intencionalidade, o que dificulta o acesso a ela. Sua aparição se dá no inconsciente, de que a obra-de-arte constitui um medium de reflexão. O inconsciente se manifesta em fluxos descontínuos, sem linearidade, portanto em fragmentos. Isso explica por que a verdade de uma determinada época aparece na obra de arte. Ela tem o caráter de uma historiografia inconsciente. Dessa forma a arte possui uma relação com a beleza da verdade, que merece ser conhecida: "nada existe de belo que não tenha em seu interior algo que mereça ser sabido.(fest steht, dass ohne Wissenswürdiges im Innern es kein Schönes gibt. $)^{5}$. O Symposium de Platão comprova a sintonia entre verdade e beleza: “... Eros pode testemunhar que a verdade não é desnudamento que aniquila o segredo, mas revelação que lhe faz justiça". Essa verdade não se submete a uma análise positivista, que procede normalmente sob a coerção dos critérios normativos e sob as leis da demonstração dedutiva e indutiva, negligenciando o aspecto inesgotável da natureza. Sua verdade, ao contrário - à medida que renuncia a uma linearidade - se deixa brilhar em uma aparição no belo da obra de arte. Dessa forma a elaboração de um pensamento acerca da verdade política vai buscar munição para se defender das generalizações, na forma dos ensaios, pequenos tratados, no Konvolut das Passagens, estudos dissertativos, produzidos desde a Metafísica da Juventude à fase da maturidade. Eles deixam transparecer de maneira pulverizada o "enigma" de uma tematização política, que privilegia o singular e a diferença. A dificuldade aparente na conexão de um sentido ao outro se traduz em uma espécie de hermenêutica. Nela permanece velado o verdadeiro objetivo da unidade, ou seja, a desconstrução criteriosa do totalitarismo subjacente, frente ao qual estaria fadado a desaparecer o particular e sua força revolucionária. Vem da singularidade e principalmente da força de sua unidade a prática de uma política democrática. Assim, a pigmentação ideológica dos totalitarismos é o alvo dos estilhaços significativos disparados pela iluminação profana do pensamento crítico de Benjamin, que se encontra na conceituação das diferenças constituintes da beleza do todo, apresentadas em forma de elementos isolados e heterogêneos (aus Einzelnem und Disparatem treten sie zusammen).

\footnotetext{
${ }^{4}$ BENJAMIN, Ursprung des deutschen Trauerspiels, Frankfurt am Main: Suhrkamp, 1978, S. 11

${ }^{5}$ BENJAMIN, Ursprung, u 159.
} 
Eles não deixam de manifestar "o impacto transcendente quer da imagem sagrada quer da verdade". 6 método de exposição em que "o fragmentário tem primado sobre o sistemático" consiste em um recurso para manter garantido o apelo à convivência política necessária, despistando o desvio sectário da época dominada pelo totalitarismo. E tem em vista a tematização da democracia, no front contra o inimigo. Pois, quando a mentalidade burguesa se vê alienada, através das operações do processo de produção (Herstellungsverfahren), ela reproduz igualmente, nas metamorfoses da consciência burguesa, o mesmo processo de repetição, massificando-se a si mesma e ao mundo, apesar de uma aparente constituição para mudanças. O que predomina é o mesmo, movido pelo poder da massa. Dissolve-se a aceitação ao outro, ao diferente. $O$ apelo à identidade funciona como um talismã. E esse sentimento de identidade no processo de produção não admite a criatividade, a espontaneidade. O mundo se massifica, neutralizam-se as instâncias vitais, em prol do sacrifício ao mesmo. A não-identidade pensada por Adorno funcionaria como uma espécie de resistência ao status quo da massificação. Em Benjamin a atenção voltada ao particular diminui o desgaste provocado pela massificação através da qual o sistema ilude com a ideia falsa de novidade, com a qual manipula a massa desavisada. Benjamin observa no choque um dispositivo que pode ser canalizado como sinal de alerta. Para se alcançar o conceito "despertar" a partir do particular e de sua unidade, no Ser, é preciso ter em mente as condições abissais da Modernidade, como pós história do conflito que Benjamin descobre no trabalho filológico da arte seiscentista, na ânsia em conciliar ordem do mundo com o movimento natural das coisas, ${ }^{7}$ em suma, compreender a tensão de um mundo sem referencias - uma vez perdido o elo que unia o homem à transcendência, naquele contexto da Reforma - e sobretudo tendo ainda que enfrentar a catástrofe da perda do ethos histórico e, portanto, despojado de garantias. e do apoio outrora assegurado pela religião objetiva. Refiro-me ao gesto de desgarrar-se dos condicionamentos em que a espontaneidade do homem, coibida como ato blasfemo contra as leis da abstração conceitual, no segmento estatal absolutista, por exemplo, inseria-se no plano do profano, sob a égide da expropriação dos bens eclesiásticos, onde se dispersa não somente o elemento material. Toda a relação dessa mentalidade com o anímico se desvincula daquilo concebido anteriormente como

\footnotetext{
${ }^{6}$ BENJAMIN, Ursprung...S. 10

7CALLADO, "o drama da alegoria no século XVII barroco", 2004, p. 135.
} 
sacralidade. Ela migra para outros segmentos da instituição, para a política, por exemplo. A política passa a preencher o espaço da credibilidade negado à religião. Ela se transforma em ideologia, ao assimilar aqueles remanescentes teológicos expatriados pelo novo elemento dominante - a verdade científica, uma vez absolutizada pela "racionalidade" do Século das Luzes. A ciência passa a ter o prestígio do qual a religião gozava em outros tempos - prestígio da Fé. É justamente sobre o dogma político - aqui é preciso dar realce a essa constatação - dogma esse consolidado em forma de síntese ideológica nos totalitarismos da modernidade sejam políticos ou filosóficos - que sugerimos dialogar tendo em vista um novo arranjo metodológico para a reflexão, agora incólume a condicionamentos, no dizer de Benjamin, liberta do preceito doutrinário imperativo. ${ }^{8}$ llustro essa ideia com um ensaio de Marramao sobre as gnoses da Modernidade, "reconhecíveis no denominador comum da autodivinização do homem", 9 a partir da evidência do desaparecimento das concepções divinatórias, na mentalidade da estética barroca, ou seja, na realidade do Deus absconso da ética luterana, e, para agravar ainda mais, justamente quando o objeto de culto é capturado ante o furor ctônico gerido pelo antropocentrismo nascente. Ele se deixa confiscar pela ciência política, quando esta se revolve na própria cintilação, no momento em que passa a ser o expoente da verdade. Essa concepção sobre o processo de secularização que transforma as coisas de deus em coisas do mundo, já temidas por Santo Agostinho, são referidas por Marramao, e acordadas na obra de Erich Vögelin ${ }^{10}$ Assim persistiria em estudos teóricos da modernidade - complementa Topitsch, referindo-se à doutrina marxiana para a política de seu tempo - "a imanentização hegeliana do sistema triádico da divindade que se torna autoconsciência ao finitizar-se no mundo"11. Na trilha da mesma percepção, ou seja, de uma dogmatização derivada da concepção divinatória e migrada para o plano do profano, ou seja, exercitada na política, teríamos na concepção do Gogarten do ensaio Kulturund Religion da obra Illusionen, eine Auseinandersetzung mit dem Kulturidealismus, original de 1926 (pp. 139-141) o secularismo, fenômeno das "religiões políticas", com sua pretensão de absolutizar

8 BENJAMIN. Origem do drama barroco alemão, Tradução de Sérgio Paulo Rouanet, São Paulo: Brasiliense, 1984, p. 50.

9 MARRAMAO. Céu e terra, Tradução de Guilherme Alberto Gomez de Andrade, São Paulo: Fundação Editora da UNESP, 1997, 95.

${ }^{10}$ VÖGELIN Anamnesis.ZurTheorie der Geschichte und Politik, München, 1966, p.196.

${ }^{11}$ TOPITSCH. "Marxismus und Gnosis" in:__Sozialphilosophie zwischen Mythos und Wissenschaft. Neuwied-Berlin, 1969. 
o agir humano e de totalização das instituições político-sociais, em outras palavras: "desenraizamento das formas de vida tradicionais". ${ }^{12}$ Mais uma vez podemos nos referir à relação-exclusão entre a cidade de Deus e a cidade dos homens. Os homens pretendem esconder a necessidade do divino com sua auto-imagem, agora ela própria divinizada. Doravante ele passará a ter a ilusão de se movimentar bem diante dos percalços, para a solução dos quais se recorria antes a Providência. Nos tempos modernos, é preciso acrescentar que esse fenômeno foi possibilitado pelo desvio da subjetividade e seu extravasamento, agora de forma canônica e sectária, e tendo em vista os diferentes estratos da política. Concluímos esse tema, apontando ligeiramente, como um dos nódulos, visíveis na investigação da Organização estatal da Modernidade, a secularização. Ela seria outro estágio da sacralização, de que não estão isentos os sistemas políticos aludidos, ou seja, os que atuam ideologicamente, devedores de uma "estrutura mística da autoridade", como já havia preconizado Michel de Montaigne, ${ }^{13}$ em linguagem mais atual, de um culto da personalidade, de uma subjetividade inflada, ou ainda, remontando à antiguidade, de um "nomos empsychos", ou lei viva, que, desde os clássicos antigos, o mundo conheceria. Repetimos: a secularização seria outra forma de culto ao sagrado, não mais processada pelo dogma de revelação, mas professada na consciência embotada pelo fragor ideológico da salvação irradiado em um processo de redivinização da sociedade como chave que desvela a "intima lógica do desenvolvimento político ocidental". ${ }^{14}$ Atribui-se ao mesmo fenômeno, o aparecimento de sua contra-moeda: a concepção do capitalismo como religião, na análise benjaminiana das bases ideológicas que sustentam a mentalidade profana atual. ${ }^{15}$ Religião puramente de culto, talvez a mais extrema que já houve, que não conhece nenhum dogma especial, nenhuma teologia, e sob a qual o utilitarismo ganha nuanças e matizes religiosos. O capitalismo é o primeiro caso de um culto que nunca dá a chance de expiação, portanto de um culto sempre devedor. O típico do pensamento sobre a religião capitalista encontra-se, expressivamente, em Nietzsche. Encastoado nele se revelam as variantes das gnoses político-

\footnotetext{
${ }^{12}$ MARRAMAO, Céu e Terra, p. 99. Mais uma vez podemos enfatizar aqui aquela relaçãoexclusão já antevista por Agostinho entre a cidade de deus e a cidade dos homens.

${ }^{13}$ MONTAIGNE, “Ensaios III" in:_Os Pensadores, São Paulo: Nova Cultural, 1988, p. 141.

${ }^{14}$ VÖGELIN. Wissenschaft, Politik und Gnosis, 1966.P. 196.

${ }^{15}$ BENJAMIN. Kapitalismus als Religion in:_Gesammelte Schriften, Band VI, Frankfurt am Main: Suhrkamp Verlag, 1977, S. 100.
} 
econômicas. Elas arrefeceriam o apelo ao transcendental "tragando o divino para dentro do foro da interioridade". Com isso constrói-se o mito da personalidade da qual a instituição é a forma autorizada. Na medida em que a projeta para além da massa amorfa, cria derivações como identidade, sujeito, autonomia, terminologias destinadas a empanar a realidade da massificação e do domínio com suas tentativas de homogeneização do mundo. Vögelin vai chamar a esse ato o de imanentizar o significado da existência. Também pra Benjamin o apelo à imanência historicamente se inicia ao se experimentar o constrangimento diante de uma transcendência inalcançável, a palavra correta seria, desesperança ou desconsolo, que leva o homem a espojar-se entre signos, rótulos e emblemas na busca de sentido. diante de uma transitoriedade inalienável. A auto redenção constituiria a chave explicativa da Modernidade da gnose, explica ainda Vögelin. Vögelin compara o apelo a gnose às primeiras imanentizações medievais do eschaton, sendo agora outro o ponto de apoio, não mais Deus. O próprio homem aparece como signo. Segundo Freud, "se você quiser expulsar a religião de nossa civilização europeia, só poderá fazê-lo através de outro sistema de doutrinas, e esse sistema, desde o início, assumiria todas as características psicológicas da religião - a mesma santidade, rigidez e intolerância, a mesma proibição do pensamento - para sua própria defesa." ${ }^{16} \mathrm{Com}$ essa lógica atuaram e continuam atuando os totalitarismos. O processo de desdivinização do mundo e redivinização, onde o homem pretende assumir o "papel" de Deus, se alastraria pelo "humanismo, progressismo, liberalismo, positivismo. Chegando ao marxismo, com sua ideia de "revolução total" constituiria a forma extrema dessa secularização perversa" 17 Também o filósofo austríaco Topitsch, fiel a sua inspiração antidialética,

\begin{abstract}
"identifica o centro de irradiação da influência gnóstica sobre as ideologias contemporâneas numa particular forma de pensamento: a do idealismo alemão. Aqui teriam sido refundidos os elementos salvíficos e escatológicos das correntes neoplatônicas, gnóstico-herméticas e cabalistas presentes no contra-iluminismo alemão entre os séculos XVIII e XIX. E deste modo ter-seia difundido a postura mitológica e anticientífica típica de muitas das ideologias utópico-revolucionarias contemporâneas e, acima de todas, do marxismo, que representa para Topitsch a verdadeira e própria gnose da Modernidade" ${ }^{\prime 18}$.
\end{abstract}

\footnotetext{
${ }^{16}$ FREUD, O Futuro de uma llusão, Tradução José Octávio de Aguiar Abreu, Rio de Janeiro: Imago, 1997, p. 79-80.

${ }^{17}$ MARRAMAO, p. 96

${ }^{18}$ MARRAMAO, p. 98
} 
Para Benjamin, no processo de igualdade dos socialismos modernos se dá a fratura da unidade do singular e o esvanecimento de sua força para reproduzir a alteridade. O contraponto a esse status quo é feito de forma monadológica, convocada a percepção para o diferente, como já praticaram de forma exemplar direta ou indiretamente os antigos. Cito Etienne de La Boetie, alertando sobre o risco do dogmatismo, com o "Discurso sobre a servidão voluntária", Jean-Bodin, chamando a atenção para a inexistência de um código único para gerir a coisa pública e mesmo Maquiavel, com seu faro para o princípio antropológico, sobre o qual fundou um raciocínio político consequente. Esses expoentes ao colocarem a habilidade política em uma engrenagem linguística cifrada a orientar o estadista, não foram de todo imunes à rejeição de suas teorias, uma vez que a fundação do código para o comportamento é a mesma da lei positiva. Nela a força para a justiça se esvai na padronização, na medida em que é desconsiderado o valor do singular. Essa redução a um padrão e a um rótulo se origina no mito. Assim nem mesmo o sistema jurídico e a lei positiva escapam de sua derivação no poder mítico. A experiência do estadista barroco ao abrir o estado de sítio político na alma - na forma como é valorizada na cena da dramaturgia barroca - tem outra origem. Ela se baseia na experiência singular, que desperta a sua interioridade. Proporcionar um "saber lidar com os fatos" e com a facticidade exige um conhecimento de base antropológica, enraizado nas leis da calculabilidade do agir, na criatura, que se dilata na ideia destinada à descrição do humano, enquanto configuração em que um ato extremo do agir se encontra com o outro extremo, entendendo-se sob essa ideia, a gama de conceitos vinculados ao comportamento. A "exceção" do estadista seria a atitude de transformar "a dinâmica da história em uma ação política", diz Benjamin no Trauerspielbuch, e para a qual é convocada toda a força do conhecimento nos jogos da tradição. Acumular saber transmitido de uma geração a outra é construir experiência. Recordemos o momento em que a gruta hibernal do absolutismo é iluminada pelo conhecimento da singularidade em que o monarca se identifica com o menor dos governados pela vivência de uma origem comum, justamente quando (e aqui cito de novo Benjamin) "o poder de animalidade e dos afetos, sobretudo o amor e o medo, sua ausência de limites são convidados ao palco da atividade política e confrontados à inteligência e à vontade." ${ }^{19}$ É justamente no conflito entre essas

\footnotetext{
${ }^{19}$ BENJAMIN, Origem do drama barroco alemão, Opus cit, p. 118.
} 
forças, que se dá o estado de exceção. E ele acontece de fato, apesar dos entraves que o espírito enfrenta, enredado em outros interesses, e negando toda a tradição do mito cristão, para se revelar enquanto "faculdade de exercer a ditadura", em nome do código legiferante do sistema jurídico do principado barroco. Apesar dessa constatação funesta o estado de exceção se realiza para salvar o outro. O estado de exceção é alimentado pela singularidade e força de sua unidade, vinculada à frágil força messiânica, a despeito de toda coerção ideológica exercida sobre as leis naturais da espontaneidade e da boa vontade. Reconstruindo o pensamento sobre 0 conceito limite de soberania em Carl Schmitt: "soberano é aquele que decide em um estado de exceção" (Souverän ist, wer über den Ausnahmezustand entscheidet), ${ }^{20}$ mostra Benjamin que soberano é aquele que, rompendo com as arestas de sua consciência mergulhada no êxtase absolutista, decide em favor do outro, exercitando o verdadeiro estado de exceção na alma, e ele o faz por encontrar em sua singularidade, a mesma unidade do particular, através da qual se identifica com o súdito menor. Essa unidade se encontra na origem de ambos - na experiência de uma origem comum - a condição humana. Relembro aqui e é sempre bom lembrar de novo a tragédia de Antígona, ao auscultar as leis morais do coração. No caso da dramaturgia barroca, essa mesma experiência em dar ouvidos à lei moral, inscrita, não no cânone político, mas na própria dignidade, a mais inusitada, nas contingências políticas do absolutismo, consegue fraturar o poder, invalidando a normatividade do Direito Constitucional que transfere para o rei as insígnias da origem adâmica, particularmente defendidas pro Robert Filmer, em O Patriarca. Sustando toda essa avalanche mítica, o estado de exceção político antevisto na camada metafísica da dramaturgia barroca, se torna possível no apelo à singularidade do estadista, e não na celebração de sua personalidade. A exceção esgarça a subjetividade, em nome do particular. Como em Jacques Derrida essa desconstrução política constitui a justiça. Há muito ela exilou-se da consciência da Modernidade, para esconder-se no inconsciente. E é diante do embotamento da consciência pelo narcótico ideológico que a percepção de Benjamin alcança o desenrolar das metamorfoses da consciência burguesa como um grito último de libertação que fica inaudível. Ao contrário do que conjecturava a tradição acerca do coletivo, verifica-se nele o esmagamento da espontaneidade, enquanto a força

\footnotetext{
${ }^{20}$ SCHMITT. Politische Theologie, Berlin: Duncker \& Humblot, 1996, p. 11.
} 
propulsora da verdade, na criatura, emana do particular monadológico. São as diferenças em justaposição, a representação cabível do real. Ela não dispensa o outro. Supõe entrecruzamentos recebendo de cada unidade a qualificação para medir a dinâmica das interações. A maneira da mutualidade e da reciprocidade visíveis em uma mônada, contraria o senso comum na base em que é pensado o coletivo para o momento positivista. $O$ singular, seja ele na sua diferença, revolve a generalização conceitual que assedia o pensamento. Acena para a perda do senso crítico perante a expansão da subjetividade e tenta recuperá-lo do ilogismo na expressão da experiência. Subjetividade e singularidade são conceitos excludentes. Se a subjetividade cria pelo desejo, a tenacidade do singular destrói a subjetividade para poder criar. A força do singular encontra-se na experiência transmitida entre as gerações. Ela forma uma cadeia de saberes, recolhidos pela memória. Nas comunidades orgânicas da tradição a figura do narrador representa um modelo da particularidade atuando com a força de sua unidade. Ao recepcionar a tradição, cada nova singularidade a recria, acrescentando aos bens culturais o seu quinhão de conhecimento. Esse recolhimento vai gerando a competência. Estruturada sobre ela vem a autoridade natural que consiste num saber de fato, não de posse (Erkenntnis ist ein Haben) ${ }^{21}$. A ausência da sabedoria gera o autoritarismo, e seu fundamento vazio, apoiado na linguagem com sua retórica, no discurso grandiloquente da propaganda, "tagarelice" pura no dizer de Benjamin, somente capaz de convencer a massa, mas não o singular com sua unidade. Uma vez que a lógica arbitrária do coletivo parte de um código, mera convenção ou sinal emblemático não mais capaz de dar conta das sutilezas linguísticas, na expressão política da democracia, o pensamento deve ser capaz de reelaborar o que, a partir do solo material da história, foi edificado e nessa mudança de paradigmas refletir significa fazer uma "imersão no pormenor do conteúdo material", aconselha Benjamin, pois o pensamento suporte de abstrações lógicas, no conceito, enredado na evidência cartesiana, adquirida na cadeia de razões, declina na sua capacidade de definir o "fenômeno da modernidade", caracterizado pela indefinição. A situação se agrava quando a definição arbitrária do conceito recorre à palavra como meio (Mittel), e a linguagem enquanto comunicação do abstrato, a partir da queda, quando o homem já não tem o poder de comunicar o concreto. Para Benjamin o movimento surrealista, "último

\footnotetext{
${ }^{21}$ BENJAMIN, Origem do drama barroco alemão, Opus cit, p. 51
} 
instantâneo da inteligência europeia" foi o mais apropriado a auscultar o abalo da linguagem, esculpida para a comunicação em seus desregramentos. Cai juntamente com ela o Eu concebido isoladamente, ou seja a subjetividade, dando lugar à expressão do inconsciente. O Surrealismo - movimento tanto político como estético cede à verdade do singular no inconsciente. Ele percebe o abalo da subjetividade, através do êxtase, elemento revolucionário, expatriado da racionalidade e que retorna como recalque. Constituindo o elemento propulsor da crítica, no ato revolucionário, ele eclode fetichizado e em forma de subjetividade, de dentro do coletivo. Torna-se um empecilho na referencia à verdadeira revolução contra as forças arcaicas do mito: a revolução disciplinada do singular, que se faz no inconsciente. O conceito de coletivo nutrido na consciência gera uma babel de interesses disfarçados anuviando a verdadeira válvula propulsora que imerge das singularidades contra a estagnação do mesmo. Falemos agora do seu antídoto: a força da experiência aquela capaz de recolher o conhecimento da história e transformá-lo em ação política na medida em que prepara o estadista para tomar a decisão. Não são os sistemas políticos responsáveis pelo desajuste e desfaçatez e sim a inexistência do singular com sua unidade. Ele é imune às uniformizações levadas avante pela dominação. Contraponto no inconsciente, cuja força Benjamin descobre no surrealismo, alcançamos a denúncia à padronização que rechaça a força do singular e seu impulso em atingir a completude no outro. Agambem encontra na singularidade a base para uma outra comunidade, "a comunidade que vem". Ela não irá renunciar a um qualquer, conceito positivo, liberto de titulações, rótulos canônicos, emblemas. Tomás de Aquino designou-o quodlibet. $\mathrm{Na}$ enumeração escolástica dos transcendentais, precisamente na Suma Teológica de Aquino qualquer ente que se queira é "uno, verdadeiro, bom ou perfeito" (quodlibet ens est unum, verum, bonum, seu perfectum). ${ }^{22}$ Pois o amor, diz Agamben, "não se dirige jamais a esta ou aquela propriedade do amado" ${ }^{23}$ (ser pequeno ou negro ou cristão) mas tampouco prescinde dela em nome da insípida generalidade. O ser feliz, de posse de seus predicados e podendo fazer uso deles é íntegro, (Aqui abro um parêntese para lembrar Benjamin aludindo à felicidade do homem antigo, amparado pela sua vida plena. Continuo com Agamben, para quem "ele (o amor)

\footnotetext{
${ }^{22}$ AGAMBEN. A comunidade que vem . Tradução de Cláudio Oliveira, Belo Horizonte: Autêntica Editora, 2013, p. 11.

${ }^{23}$ Idem, ibidem.
} 
quer o ser com todos os seus predicados, o seu ser tal qual é". ${ }^{24}$ Ele deseja "o qual ( quodlibet) somente enquanto é tal" 25 - com os seus predicados - e esta singularidade é a sua particular magia.

\section{REFERÊNCIAS}

AGAMBEN, Giorgio, A comunidade que vem, tradução de Cláudio Oliveira, Belo Horizonte: Autêntica Editora, 2013.

BENJAMIN, Walter. Ursprung des deutschen Trauerspiels, Frankfurt am Main: SuhrkampVerlag, 1997.

Origem do drama barroco alemão, tradução de Sérgio Paulo Rouanet, São Paulo: Brasiliense, 1984.

BURTON, Robert, A anatomia da melancolia, Tradução de Guilherme Contijo Flores, Curitiba: Editora UFPR, 2011.

CALLADO, Tereza de Castro, "O drama da alegoria no século XVII barroco" in:_Kalagatos, Fortaleza: Eduece, 2004.

CALLADO, Tereza de Castro. Walter Benjamin - A Experiência da Origem, Fortaleza: Eduece, 2006.

DERRIDA, Jacques, Torres de Babel, Tradução de Junia Barreto, Belo Horizonte: Editora UFMG, 2002.

DIDI-HUBERMAN, George, Sobrevivência dos vagalumes, Tradução de Vera Casa Nova, Márcia Arbex, Belo Horizonte: Editora UFMG, 2011.

FREUD, O futuro de uma ilusão, Tradução de José Octávio de Aguiar Abreu, Rio de Janeiro: Imago, 1997.

MARRAMAO, Giacomo, Céu e Terra, tradução de Guilherme Alberto Gomez de Andrade, Fundação Editora da UNESP, 1997.

MONTAIGNE, Michel de, "Ensaios III" in:_Os Pensadores, São Paulo: Nova Cultural, 1988.

SCHMITT, Carl. Politische Theologie, Berlin: Duncker \& Humblot, 1996.

SCHLEGEL, Friedrich, O dialeto dos fragmentos, Tradução de Márcio Suzuki, São Paulo: Editora lluminuras Ltda, 1997.

\footnotetext{
${ }^{24}$ Idem,ibidem.

${ }^{25}$ Idem, ibidem.
} 
WEIL, Simone, Opressão e liberdade, tradução de Ilka Stern Cohen, São Paulo, Bauru: Editora da Universidade do Sagrado Coração - EDUSC, 2001. 